\title{
Fourier Transform Infrared (FTIR) spectroscopy to monitor the cellular impact of newly synthesized platinum derivatives
}

\author{
GILLES BERGER $^{1}$, RÉGIS GASPER ${ }^{4}$, DELPHINE LAMORAL-THEYS ${ }^{2}$, ANJA WELLNER $^{5}$, MICHEL GELBCKE $^{1}$, \\ RONALD GUST $^{5,6}$, JEAN NÈVE ${ }^{1}$, ROBERT KISS $^{3}$, ERIK GOORMAGHTIGH ${ }^{4}$ and FRANÇOIS DUFRASNE ${ }^{1}$ \\ ${ }^{1}$ Laboratoire de Chimie Pharmaceutique Organique, ${ }^{2}$ Laboratoire de Chimie Analytique, Toxicologie et Chimie Physique \\ Appliquée, and ${ }^{3}$ Laboratoire de Toxicologie, Institut de Pharmacie; ${ }^{4}$ Laboratory for the Structure and Function of \\ Biological Membranes, Center for Structural Biology and Bioinformatics, Faculty of Sciences, Université Libre \\ de Bruxelles (ULB), Brussels, Belgium; ${ }^{5}$ Institute of Pharmacy, Free University of Berlin, Berlin, Germany; \\ ${ }^{6}$ Institute of Pharmacy, Leopold-Franzens-Universität, Innsbrück, Austria
}

Received March 15, 2010; Accepted April 30, 2010

DOI: 10.3892/ijo_00000717

\begin{abstract}
Platinum complexes remain widely used to combat various types of cancers. Three platinum complexes, cisplatin, carboplatin and oxaliplatin, are marketed for various oncological purposes. Additionally, nedaplatin, lobaplatin and heptaplatin have gained regionally limited approval for oncology purposes. Furthermore, various platinum derivatives are currently under clinical trials. More than 40 years after their discovery, however, the precise mechanism of action of platinum antitumor complexes remains elusive, partly because these compounds display numerous intracellular targets. Structure-activity-relationship analyses are therefore difficult to conduct to optimize the synthesis of novel platinum derivatives. The aim of the present study is to illustrate the potential of using Fourier Transform Infrared (FTIR) analyses to monitor the cellular modifications induced by the new platinum derivatives that we have synthesized. We show in the present study the advantages of combining an in vitro assay to determine the $\mathrm{IC}_{50}$ growth inhibition concentrations of a series of compounds belonging to a given chemical series and FTIR analyses carried out at the $\mathrm{IC}_{50}$ concentrations for each compound to identify potential hits within this series of compounds. The original pharmacological approach proposed here could, therefore, avoid large-scale pharmacological experiments to find hits within a given chemical series.
\end{abstract}

Correspondence to: Dr Robert Kiss, Laboratoire de Toxicologie (CP205/1), Institut de Pharmacie, Université Libre de Bruxelles, Campus de la Plaine, Boulevard du Triomphe, 1050 Bruxelles, Belgium

E-mail: rkiss@ulb.ac.be

Key words: Fourier Transform Infrared spectroscopy, platinum derivatives

\section{Introduction}

Platinum complexes remain widely used to combat various types of cancers (1). Three platinum complexes, cisplatin, carboplatin and oxaliplatin, are marketed for oncological purposes (Fig. 1). Nedaplatin, lobaplatin and heptaplatin have gained regionally limited approval, and various other platinum derivatives are currently under clinical trials (1-3). However, platinum compounds present several drawbacks, such as numerous and serious side effects (4), a limited spectrum of activity, development of resistant cancer cells (5) and unfavorable pharmacokinetic profiles (6). Solutions to these problems have been partially found with oxaliplatin (belonging to the so-called third generation of antitumor platinum complexes), which is less toxic and especially active against several types of tumors known to be less responsive to cisplatin $(7,8)$. These properties have been attributed to the 1,2-diaminocyclohexane moiety that is thought to strongly influence the biological profile of the drug (9). Starting from this hypothesis, numerous classes of new platinum complexes have been designed, among which platinum (IV) complexes (10), trans-complexes (11), polynuclear compounds (12) and hybrid complexes, i.e., platinum bound to biologically relevant molecules (13), are particularly interesting. However, more than 40 years after their discovery, the precise mechanism of action of platinum antitumor complexes remains particularly elusive, partly because these compounds display numerous intracellular targets $(14,15)$. Structure-activity-relationship analyses are therefore difficult to conduct to optimize the synthesis of novel platinum derivatives. Our group has already synthesized various Pt(II) complexes structurally related to 1-phenyl-alkane-1,2-diamines (Fig. 1); those substituted by a fluorine atom at position 4 of the aromatic ring display significant anticancer activity in vitro (16-19).

The aim of the present study was to illustrate the potential of using Fourier Transform Infrared (FTIR) analyses to monitor the cellular modifications induced by the new platinum derivatives that we have synthesized and that are illustrated in Fig. 1. We recently made use of this novel 
approach to characterize the anticancer effects of sodium pump inhibitors (20).

\section{Materials and methods}

Chemistry. The complexes (labeled 4-10 in Fig. 1) have been synthesized using the methods we detailed previously (16-19). Briefly, the diamines have been obtained starting from diversely substituted benzaldehyde derivatives and through the hydrocyanation of their corresponding imines followed by the reduction of the nitrile (21). Then the complexes were isolated by reaction of the diamines with $\mathrm{K}_{2} \mathrm{PtCl}_{4}$ (precipitation, filtration, washing with $2 \mathrm{~N} \mathrm{HCl}$ and drying at $60^{\circ} \mathrm{C}$ under vacuum) (22). All of these compounds have been characterized by ${ }^{1} \mathrm{H}$ - and ${ }^{13} \mathrm{C}-\mathrm{NMR}$ and IR $(16-19,21,22)$.

Cancer cell lines, media and cell culture conditions. The cell lines used in this study included human U373 (ECACC, European Collection of Cell Culture, Salisbury, UK, code 89081403) and Hs683 (ATCC, American Type Culture Collection, Manassas, VA, USA, code HTB-138) glioblastoma lines, A549 (DSMZ, Deutsche Sammlung von Mikroorganismen and Zellkulturen; Braunschweig; Germany, code ACC107) non-small cell lung cancer (NSCLC), MCF-7 (DSMZ code ACC115) and MDA-MB-231 (ATCC code HTB26) breast cancer lines, OE21 esophageal cancer (ECACC code 96062201) and SKMEL-28 (ATCC code HTB-72) melanoma cell lines.

The cells were incubated at $37^{\circ} \mathrm{C}$ in sealed (airtight) Falcon plastic dishes (Nunc, Invitrogen SA, Merelbeke, Belgium) in a humidified atmosphere of $5 \% \mathrm{CO}_{2}$. The cells were kept in exponential growth phase in MEM medium supplemented with $10 \%$ fetal bovine serum (FBS), 1\% penicillin/ streptomycin (an antibiotic/antimycotic solution) and 1\% kanamycin to prevent mycoplasms. Cell culture medium and FBS were purchased from Gibco (Invitrogen, Merelbeke, Belgium). Penicillin/streptomycin and kanamycin solutions were provided by Sigma-Aldrich, SA (Bornem, Belgium).

Determining $I C_{50}$ in vitro growth inhibitory concentrations. The overall growth level of human and mouse cancer cell lines and human normal cell lines was determined using the colorimetric MTT (3-[4,5-dimethylthiazol-2yL-diphenyl tetrazolium bromide, Sigma, Belgium) assay (23-25). Briefly, the cell lines were incubated for $24 \mathrm{~h}$ in 96-microwell plates (at a concentration of 10,000-40,000 cells/ml culture medium depending on the cell type) to ensure adequate plating prior to cell growth determination. The assessment of cell population growth by means of the MTT colorimetric assay is based on the capability of living cells to reduce the yellow MTT to a blue product, formazan, by a reduction reaction occurring in the mitochondria. The number of living cells after $72 \mathrm{~h}$ of culture in the presence (or absence: control) of the various compounds is directly proportional to the intensity of the blue color, which is quantitatively measured by spectrophotometry, in our case using a Biorad Model 680XR (Biorad, Nazareth, Belgium) at $570 \mathrm{~nm}$ (with a reference of $630 \mathrm{~nm}$ ). Each experiment was carried out in sextuplicate.

Validation of MTT colorimetric assay-generated data by means of the crystal violet assay. The in vitro testing of the substances for antitumor activity in adherent growing cell lines was carried out on exponentially dividing human cancer cells according to a previously published microtiter assay $(26,27)$. Exponential cell growth was ensured during the whole time of incubation. Briefly, $100 \mu 1$ of a cell suspension was placed in each well of a 96-well microtiter plate at 7200 cells/ml (MCF-7) and at 3000 cells/ml (MDA-MB-231) of culture medium and incubated at $37^{\circ} \mathrm{C}$ in a humidified atmosphere $\left(5 \% \mathrm{CO}_{2}\right)$ for 6 days. By removing the medium and adding $200 \mu \mathrm{l}$ of fresh medium containing an adequate volume of a stock solution of metal complex, the desired test concentration was obtained. All complexes tested were dissolved in DMF. Eight wells were used for each test concentration and for the control, which contained the corresponding amount of DMF. The medium was removed after reaching the appropriate incubation time. Subsequently, the cells were fixed with a solution of $1 \%(\mathrm{v} / \mathrm{v})$ glutaric dialdehyde in phosphate buffered saline (PBS) and stored in PBS at $4^{\circ} \mathrm{C}$. Cell biomass was determined by means of a crystal violet staining technique as described earlier $(26,27)$. The effectiveness of the complexes was expressed as corrected $\mathrm{T} / \mathrm{C}_{\text {corr }}[\%]$ or $\tau[\%]$ values according to the following equation:

$$
\begin{gathered}
\text { cytostatic effect: } \mathrm{T} / \mathrm{C}_{\text {corr }}[\%]=\left[\left(\mathrm{T}-\mathrm{C}_{0}\right) /\left(\mathrm{C}-\mathrm{C}_{0}\right)\right] \times 100 \\
\text { cytocidal effect: } \tau[\%]=\left[\left(\mathrm{T}-\mathrm{C}_{0}\right) / \mathrm{C}_{0}\right] \times 100
\end{gathered}
$$

where $\mathrm{T}$ (test) and $\mathrm{C}$ (control) are the optical densities at $590 \mathrm{~nm}$ of crystal violet extracts of the cells in the wells (i.e., the chromatin-bound crystal violet extracted with ethanol (70\%), with $\mathrm{C}_{0}$ being the density of the cell extract directly before treatment). For the automatic estimation of the optical density of the crystal violet extract in the wells, a microplate autoreader (Flashscan S 12; Analytik Jena, Germany) was used. The $\mathrm{IC}_{50}$ values were calculated from the graphs using data taken after an incubation time of $96 \mathrm{~h}$.

FITR analyses. Human A549 NSCLC cells were detached by means of a 5-min treatment with trypsin/EDTA buffer (Gibco, Invitrogen SA). The reaction was then stopped by adding 1 $\mathrm{ml}$ of culture medium. The cells were pelleted by a 2 -min centrifugation ( $300 \mathrm{~g}$ ) and washed 3 times in isotonic solution $(\mathrm{NaCl}, 0.9 \%)$ to ensure complete removal of trypsin and culture medium. The cells were then suspended in $30 \mu \mathrm{l}$ of a $\mathrm{NaCl}$ solution.

All measurements were carried out on a Bruker Equinox 55 FTIR spectrometer (Bruker, Karlsruhe, Germany) equipped with a liquid $\mathrm{N}_{2}$-refrigerated Mercury Cadmium Telluride detector. All spectra were recorded by attenuated total reflection, as detailed elsewhere $(20,28)$. Briefly, a diamond internal reflection element was used on a Golden Gate Micro-ATR from Specac (Orpington, UK), and the angle of incidence was found to be 45 degrees. Then $0.5 \mu 1$ of cell pellet was resuspended in about twice the volume of the initial pellet and was deposited on the diamond crystal (about $3 \times 10^{4}$ cells per smear). The sample was quickly evaporated under a stream of $\mathrm{N}_{2}$ to obtain a homogenous film of whole cells, as ascertained by microscope examination. The FTIR measurements were recorded between 4,000 and $800 \mathrm{~cm}^{-1}$. Each spectrum was obtained by averaging 256 scans recorded at a resolution of $2 \mathrm{~cm}^{-1}$. For statistical validation, the cells were grown in 

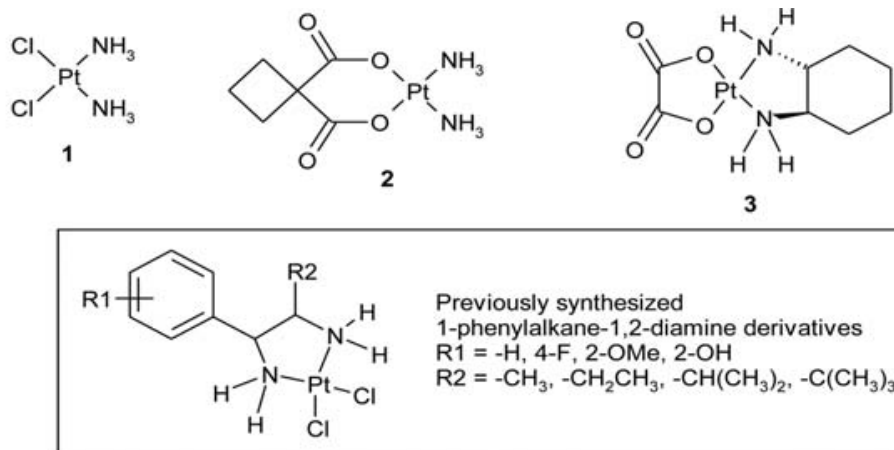

Previously synthesized

1-phenylalkane-1,2-diamine derivatives

$\mathrm{R} 1=-\mathrm{H}, 4-\mathrm{F}, 2-\mathrm{OMe}, 2-\mathrm{OH}$

$\mathrm{R} 2=-\mathrm{CH}_{3},-\mathrm{CH}_{2} \mathrm{CH}_{3},-\mathrm{CH}\left(\mathrm{CH}_{3}\right)_{2},-\mathrm{C}\left(\mathrm{CH}_{3}\right)_{3}$
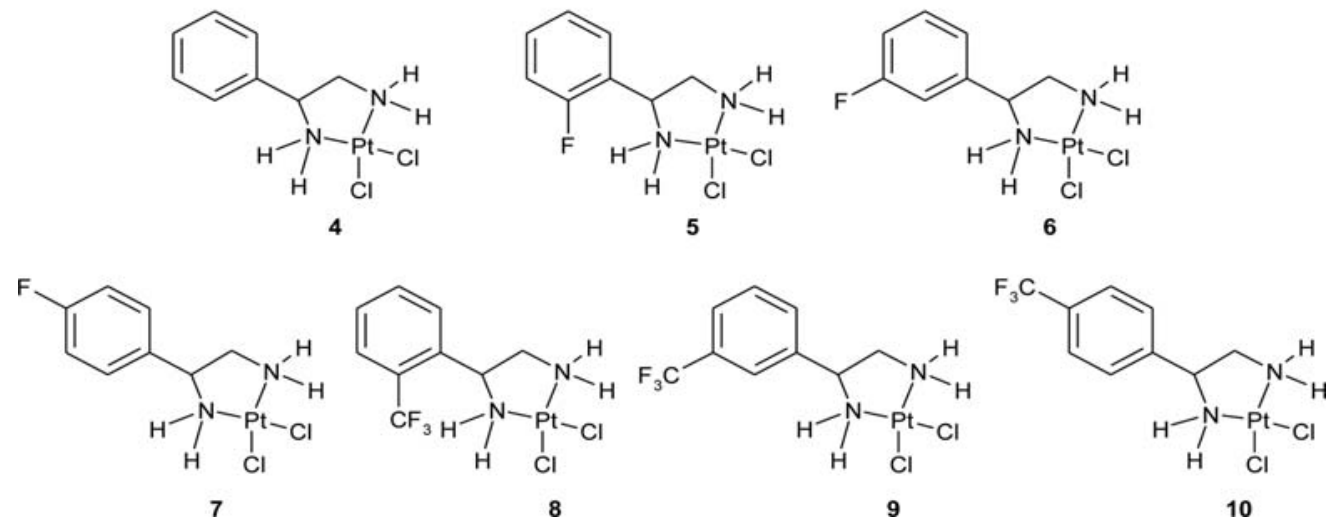

Figure 1. Commonly used antitumor Pt(II) complexes in chemotherapy [cisplatin (1), carboplatin (2) and oxaliplatin (3)], and the compounds synthesized for the present work (4-10).

Table I. Determination of $\mathrm{IC}_{50}$ in vitro growth inhibitory concentration in 6 human cancer cell lines by means of the MTT colorimetric assay.

$\mathrm{IC}_{50}$ in vitro growth inhibitory concentrations $(\mu \mathrm{M})$

\begin{tabular}{cccccccc}
\hline Compounds & $\begin{array}{c}\text { U373 } \\
\text { astroglioma }\end{array}$ & $\begin{array}{c}\text { Hs683 oligodendro- } \\
\text { glioma }\end{array}$ & $\begin{array}{c}\text { A549 } \\
\text { NSCLC }\end{array}$ & $\begin{array}{c}\text { SKMEL-28 } \\
\text { melanoma }\end{array}$ & $\begin{array}{c}\text { MCF-7 } \\
\text { breast cancer }\end{array}$ & $\begin{array}{c}\text { OE21 esophageal } \\
\text { cancer }\end{array}$ & $\begin{array}{c}\text { Mean IC } \\
\text { SEM }\end{array}$ \\
\hline 1 (Cisplatin) & $7.7 \pm 2.8$ & $69.7 \pm 7.9$ & $59.4 \pm 13.6$ & $17.9 \pm 1.2$ & $63.1 \pm 3.3$ & $4.6 \pm 0.4$ & $37.1 \pm 12.3$ \\
4 & $3.0 \pm 0.2$ & $3.9 \pm 0.1$ & $3.8 \pm 0.1$ & $3.3 \pm 0.2$ & $6.2 \pm 0.3$ & $4.5 \pm 0.2$ & $4.1 \pm 0.5$ \\
5 & $3.9 \pm 0.1$ & $3.6 \pm 0.2$ & $3.1 \pm 0.2$ & $3.2 \pm 0.3$ & $6.1 \pm 0.3$ & $6.0 \pm 0.3$ & $4.3 \pm 0.6$ \\
6 & $3.9 \pm 0.2$ & $3.9 \pm 0.3$ & $3.1 \pm 0.1$ & $2.9 \pm 0.1$ & $3.9 \pm 0.2$ & $2.9 \pm 0.2$ & $3.4 \pm 0.2$ \\
7 & $4.2 \pm 0.1$ & $4.2 \pm 0.3$ & $3.6 \pm 0.2$ & $3.9 \pm 0.1$ & $8.0 \pm 0.4$ & $4.1 \pm 0.2$ & $4.7 \pm 0.7$ \\
8 & $7.2 \pm 0.3$ & $4.2 \pm 0.3$ & $6.4 \pm 0.2$ & $4.2 \pm 0.2$ & $>10$ & $3.8 \pm 0.2$ & $>5.2$ \\
9 & $5.0 \pm 0.1$ & $4.8 \pm 0.2$ & $5.7 \pm 0.2$ & $4.1 \pm 0.2$ & $>10$ & $6.0 \pm 0.3$ & $>5.1$ \\
10 & $6.4 \pm 0.3$ & $4.4 \pm 0.2$ & $4.3 \pm 0.2$ & $7.0 \pm 0.4$ & $>10$ & $5.1 \pm 0.2$ & $>5.4$ \\
\hline
\end{tabular}

Data are presented as mean \pm SEM values calculated on sextuplicates for each compound in each cancer cell line. The cell lines have been cultured for 6 days in the absence (control) or the presence of the compounds, excepted for cisplatin for which the cells have been cultured for 3 days only with this compound.

three independent boxes for each experiment, and three samplings were taken from each box, generating a total of nine spectra per condition. For each case, 3 boxes of non-treated cells were grown, collected and analyzed in the same conditions as the treated ones for a control, generating a total of 9 non-treated cell spectra.

The FTIR data were pre-processed as follows. First, the water vapor contribution was subtracted, and then the spectra were baseline-corrected and normalized for equal area between 1765 and $950 \mathrm{~cm}^{-1}$. Finally, the spectra were smoothed at a final resolution of $4 \mathrm{~cm}^{-1}$ by apodization of their Fourier transforms by a Gaussian line. The processing of the spectra and Wilcoxon tests were carried out by means of specific software generated in our lab running in Matlab (Mathworks, Inc.).

\section{Results}

Determining $I C_{50}$ in vitro growth inhibitory concentrations. The in vitro antitumor activity of compounds 1 and 4-7 (Fig. 1) have been determined in four human apoptosis-resistant and 

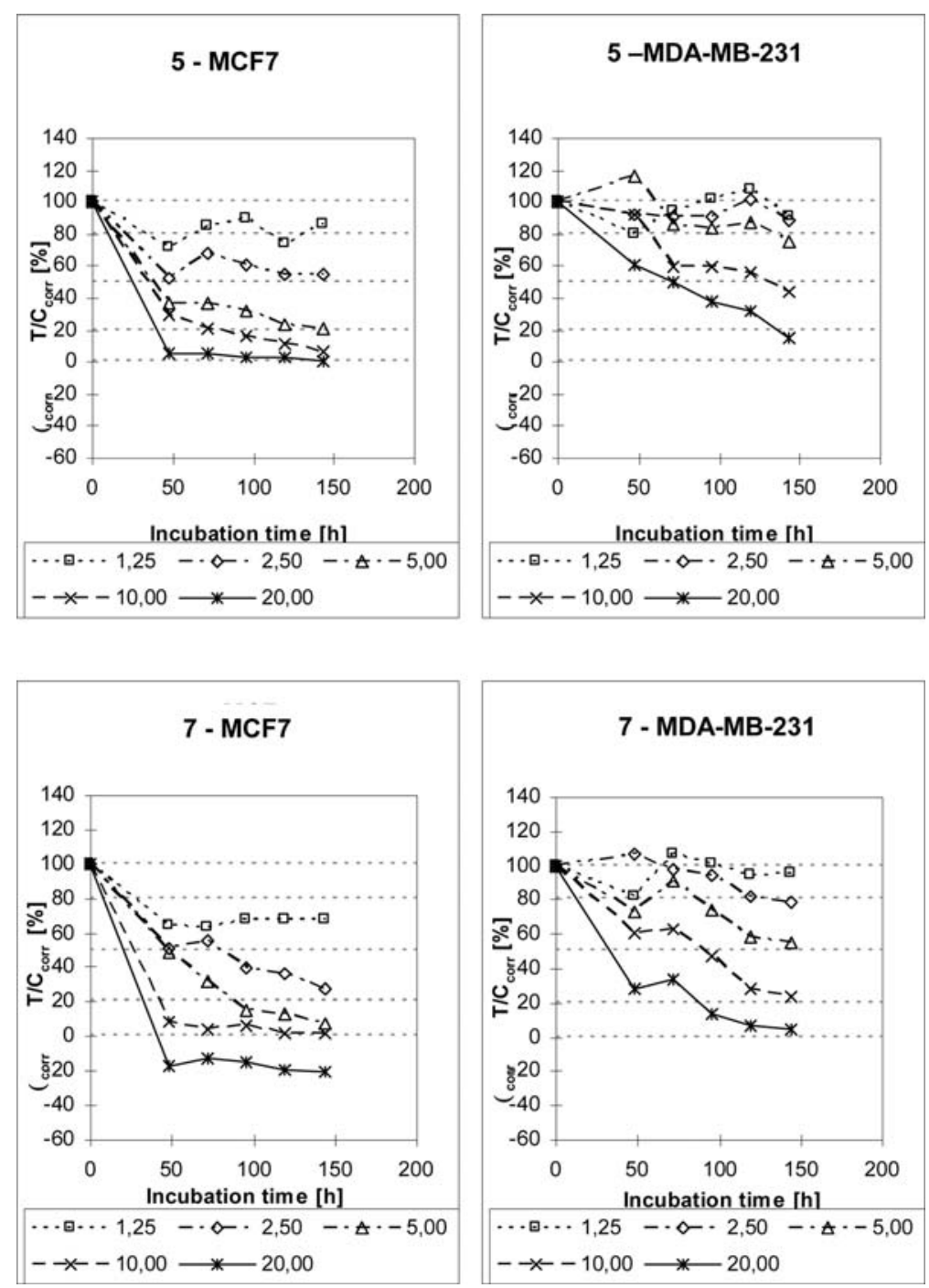

Figure 2. Time-dependent cytotoxicity of representative platinum compounds ( 5 and 7$)$ determined in the crystal violet assay. Cell biomass was determined by means of a crystal violet staining technique. The effectiveness of the complexes is expressed as corrected $\mathrm{T} / \mathrm{C}_{\text {corr }}[\%]$ or $\tau[\%]$ values according to the following equations:

$$
\begin{gathered}
\text { cytostatic effect: } \mathrm{T} / \mathrm{C}_{\text {corr }}[\%]=\left[\left(\mathrm{T}_{-} \mathrm{C}_{0}\right) /\left(\mathrm{C}-\mathrm{C}_{0}\right)\right] \times 100 \\
\text { cytocidal effect: } \tau[\%]=\left[\left(\mathrm{T}-\mathrm{C}_{0}\right) / \mathrm{C}_{0}\right] \times 100
\end{gathered}
$$

where $\mathrm{T}$ (test) and C (control) are the optical densities at $590 \mathrm{~nm}$ of crystal violet extract of the cells in the wells (i.e., the chromatin-bound crystal violet extracted with ethanol $(70 \%)$ with $\mathrm{C}_{0}$ being the density of the cell extract directly before treatment).

two human apoptosis-sensitive cancer cell lines. The four human apoptosis-resistant cancer cell lines included the U373 astroglioma $(29,30)$, the A549 NSCLC (31), the SKMEL-28 melanoma (32) and the OE21 esophageal cancer (33) cell lines. The two apoptosis-sensitive cancer cell lines included the MCF-7 breast cancer (34) and the Hs683 oligodendroglioma $(30,35)$ cell lines.

The data in Table I indicate that apoptosis-resistant and apoptosis-sensitive cancer cell lines displayed similar ( $\mathrm{p}<0.05$; Student's t-test) levels of sensitivity to the various compounds under study. This result meant that the compounds under study overcame, at least partly, the natural resistance to apoptosis displayed by many cancers associated with poor prognoses.

We used cisplatin (1) as a positive reference compound in the current assay, and the data in Table I reveal that compounds 4-7 displayed in vitro anticancer activity about 10-fold more pronounced against the various cancer cell lines under study than did cisplatin, except the U373 glioblastoma and the OE21 esophageal cancer cell lines, which displayed similar sensitivity to both cisplatin and compounds 4-7. We then decided to proceed with a second evaluation of the in vitro anticancer activity of the compounds under study by means of the crystal violet assay, as detailed below. This second series of experiments were carried out to avoid any false-negative or false-positive data that could be generated by the MTT colorimetric assay (36).

Validation of MTT colorimetric assay-generated data by means of the crystal violet assay. The time activity curves obtained with the human MCF-7 breast cancer cell line are characterized by a fast onset of antiproliferative effects. At the highest concentrations, the maximum of activity was achieved after an incubation time of $48 \mathrm{~h}$. In contrast, this effect was only observed at the end of the test (144 h) with 

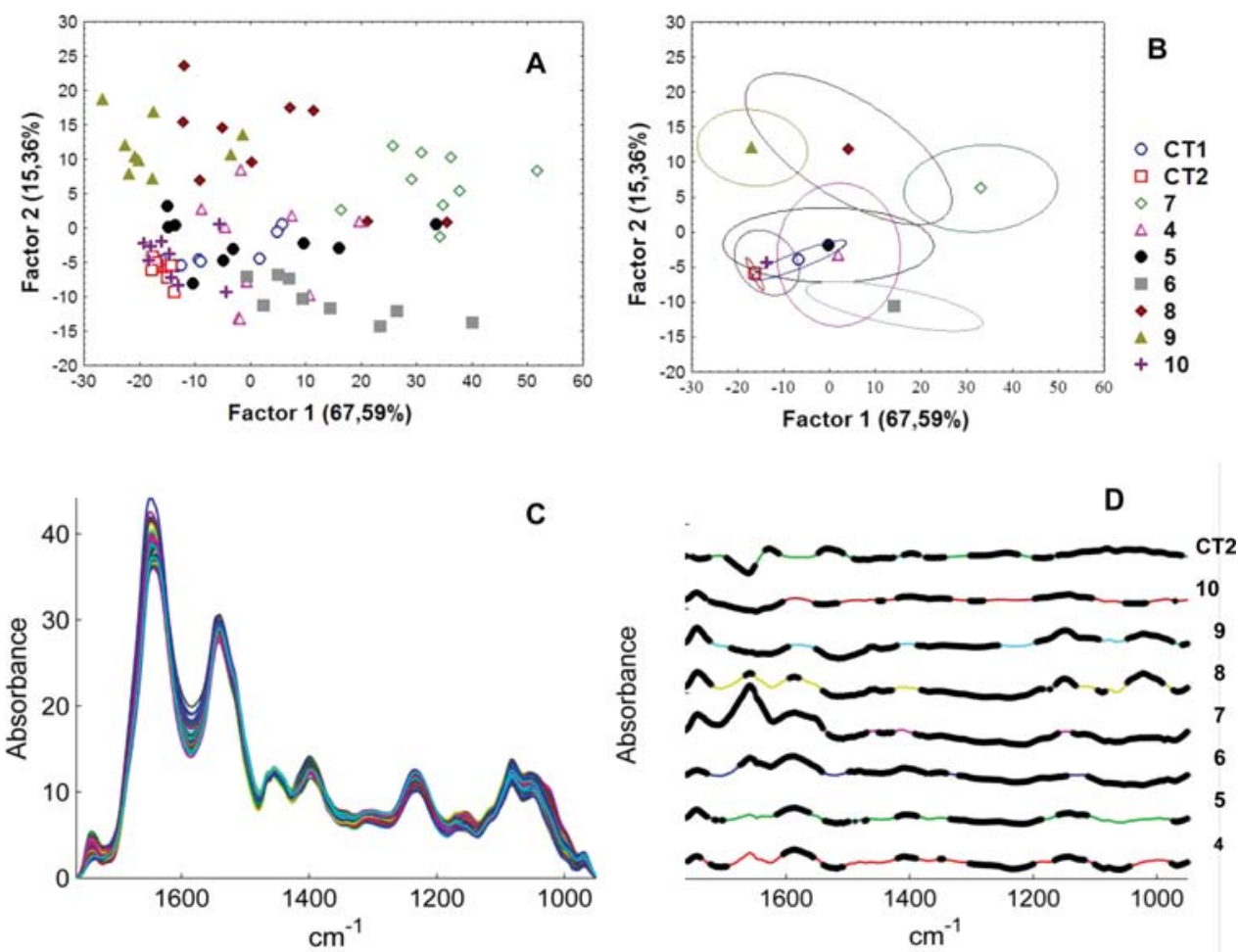

Figure 3. FTIR analysis of A549 NSCLC cells exposed to compounds 4 through 10 and control cells either not exposed to DMF (CT1) or exposed to $0.1 \%$ DMF (CT2). The latter DMF concentration mimics the concentration present for compounds 4 through 10. Three samples from three independent cultures (9 spectra) were investigated for each compound or control. The spectra are displayed in panel C between 1765 and $950 \mathrm{~cm}^{-1}$. The result of principal component analysis carried out on the entire data set appears in (A). Every compound is identified by a unique symbol defined in the right margin of the figure. The fraction of the total variance is indicated along each axis. For each compound, the mean value for the 9 replicates and the $95 \%$ confidence interval ellipses are reported in (B). (D) Reports the difference between the mean spectrum of cells exposed to a drug and the control cells (CT1). Spectra were offset along the Y-axis for better readability. Note that, as the original spectra were rescaled, the intensity of the peaks can be directly compared. Where the difference between the means was statistically significant (Wilcoxon test, $\alpha=0.005$ ), the line appears thicker.

another human breast cancer cell line, MDA-MB-231. As depicted in Fig. 2, five concentrations were used to calculate the $\mathrm{IC}_{50}$ value of each compound. Independent of the substituent in the aromatic ring, $\mathrm{IC}_{50}$ values of $2-4 \mu \mathrm{M}$ were calculated after an incubation time of $96 \mathrm{~h}$. A marginal preference in activity could be determined with the 4-F substituted complex 7, which caused cytotoxic effects at $20 \mu \mathrm{M}$ and was cytostatic at 5 and $10 \mu \mathrm{M}(144 \mathrm{~h})$. Furthermore, it must be mentioned that the exchange of the fluorine (compounds 5, 6 and 7) by a trifluoromethyl substituent (compounds 8,9 and 10) did not change the absolute cytotoxicity of these compounds in the MCF-7 breast cancer cell line. As seen in Fig. 2, only the kinetics of activity of these compounds slightly changed. In contrast, the influence of the substitution pattern was more pronounced in the MDA-MB-231 breast cancer cell line (Fig. 2). The complexes were generally less active compared to MCF-7 cells with the 2-F (5) and the 3-CF 3 (9) substituted complexes showing the highest $\mathrm{IC}_{50}$ values of 13.9 and $9.1 \mu \mathrm{M}$, respectively (Table II).

The $\mathrm{IC}_{50}$ of complexes 4-7 were also calculated by means of the MTT colorimetric assay. Similar data have been obtained between the MTT colorimetric assay (Table I) and the crystal violet assay results (Table II). When present, differences between the data generated by the two assays resulted either from the different types of measurements, i.e., viability (MTT assay) versus cell mass (crystal violet assay) measurements, or from the different incubation times used for the two assays, i.e., $72 \mathrm{~h}$ for the MTT colorimetric assay versus $96 \mathrm{~h}$ for the crystal violet assay.

FITR analyses. Human A549 NSCLC cells were cultured for 3 days in the presence of compounds 4-10 (Fig. 1) at their $\mathrm{IC}_{50}$ in vitro growth inhibitory concentrations as determined by the MTT colorimetric assay (Table I). Three independent cell cultures (i.e., three independent culture flasks) and three samples per cell culture (for a total of 9 samples) were analyzed for each compound. The 81 spectra obtained for the 9 compounds are presented in Fig. 3C. The high quality of the signal (signal/noise ratio $>3000$ ) allowed the highlight of very subtle changes induced by different compounds. Statistical analyses were performed between 1765 and $950 \mathrm{~cm}^{-1}$. This spectral area contained vibrations arising from all biological molecules (37) and provided an accurate fingerprint of cell metabolism at the time of the measurement. Thus, each of the 9 measurements available for a given compound was described by 816 wavenumbers. In other words, each sample was located at a unique position in an 816-dimensional space. To better visualize differences in locations in this 816-dimensional space between the various experimental conditions, principal component analysis (PCA) was applied to locate each sample into a bi-dimensional space defined by the first two PCA factors that described more than $80 \%$ of the variance 
Table II. $\mathrm{IC}_{50}$ (crystal violet assay) values of platinum complexes 4 to 10 .

\begin{tabular}{cccc}
\hline Compound & Residue & \multicolumn{2}{c}{$\mathrm{IC}_{50}$ values $(\mu \mathrm{M})$} \\
& & $\mathrm{MCF}-7$ & MDA-MB-231 \\
\hline 4 & $\mathrm{H}$ & $2.1 \pm 0.6$ & $8.3 \pm 0.6$ \\
5 & $2-\mathrm{F}$ & $3.2 \pm 0.4$ & $13.1 \pm 1.0$ \\
6 & $3-\mathrm{F}$ & $2.5 \pm 0.3$ & $8.3 \pm 1.0$ \\
7 & $4-\mathrm{F}$ & $1.9 \pm 0.1$ & $9.3 \pm 0.3$ \\
8 & $2-\mathrm{CF}_{3}$ & $2.8 \pm 0.5$ & $5.5 \pm 1.0$ \\
9 & $3-\mathrm{CF}_{3}$ & $3.2 \pm 0.6$ & $9.4 \pm 0.7$ \\
10 & $4-\mathrm{CF}_{3}$ & $2.9 \pm 0.5$ & $5.47 \pm 0.6$ \\
\hline
\end{tabular}

Data are presented as mean \pm SEM values calculated on triplicates for each compound in each cancer cell line.

present in the original data (Fig. 3A). A 95\% confidence interval was drawn for each compound in the bi-dimensional space defined by the first two PCA factors (Fig. 3B). The data reported in Fig. $3 \mathrm{~B}$ shows that the compound that induced the most marked metabolic modifications in human A549 NSCLC cells was compound 7 , while any chemical modifications to the scaffold of 7 (compounds 4, 5, 6, 8, 9 and 10) brought the FTIR signature back to the position of the untreated (control) A549 NSCLC cells.

Differences between the mean spectrum of cells exposed to each compound and the control (mean spectrum of non-treated cells) are reported in Fig. 3D. Each difference was the FTIR signature of the effect of the compound on the A549 NSCLC cells. Positive and negative peaks could be respectively assigned to molecules more or less abundant in the cells after $72 \mathrm{~h}$ of exposure to the compound. Thicker lines represent spectral areas that were significantly different from non-treated cell spectra, as evaluated by a Wilcoxon test $(\alpha=0.5 \%)$. The largest differences appeared for compound 7, both in the intensity and extent of spectral area, suggesting that this compound induced the most marked cellular changes in A549 NSCLC cells.

\section{Discussion}

The plasticity and instability of the cancer genome is impressive and is characterized by gene amplifications and deletions, rearrangements, and many silent and active mutations (38). Although targeted therapeutics have had effects in some diseases, there remains a large role for new cytotoxic agents that have the potential to be broadly active across multiple cancers (38). The development of metal complexes with anticancer activity has had an enormous impact on cancer chemotherapy $(38,39)$, and platinum-based regimens are the basis for treatment of several common tumors (38). Indeed, the discovery of cisplatin in the 1960s represented a landmark achievement and ushered in a new era in cancer treatment $(38,39)$. However, despite the fact that cisplatin has achieved significant clinical benefit for several types of solid tumors, its effectiveness has been hampered by toxic side effects and tumor resistance that often leads to the occurrence of secondary malignancies (39). Cisplatin was indeed one of the first chemotherapeutic agents to exhibit broad efficacy in solid tumors, and it remains among the most widely used agents in the treatment of cancer $(3,38,39)$. Its achievements have inspired great efforts to design similarly effective platinum agents that overcome the three main limitations of cisplatin: toxicity, tumor resistance and poor oral bioavailability (3). However, 40 years after the initial discovery of cisplatin, only two other platinum agents have garnered US FDA approval: carboplatin and oxaliplatin $(3,40,41)$. Although hundreds of promising agents were tested in clinical trials during the 1990s, only oxaliplatin made it past clinical development (3). Additionally, nedaplatin, lobaplatin and heptaplatin have gained regionally limited approval (40). For a brief period, the economic cost of these unsuccessful efforts retarded further efforts to develop new agents (3). Despite these challenges, however, two new exciting platinum agents have been brought to Phase III trials: satraplatin for hormone-refractory prostate cancer $(3,42)$ and picoplatin for small-cell lung cancer (3). If successful, they may inspire a new effort to bring betterdesigned platinum agents to market (3).

To successfully achieve the development of new clinically efficient platinum complexes, several attempts have been made to obtain quantitative structure-activity relationships $(43,44)$. The aim of the authors was to find general rules for guiding the design of new Pt complexes, but this approach has proven to be especially difficult. In particular, investigation of the mechanism of action of platinum complexes remained a particularly tough task. Owing to the nature of the platinum atom, which is a highly reactive Lewis acid, numerous cellular components are prone to bind the complexes, including nucleic acids (DNA and RNA), proteins and phospholipids (45). Despite this large variety of targets, however, it is commonly admitted that DNA is the most relevant biological structure responsible for their anticancer effects $(3,38-42,45)$, which has been proven by the analysis of the cellular responses triggered by platinum complex treatment, mainly in terms of protein expression (14,46-48). Upon binding of the complexes, several peptides are recruited to recognize the DNA lesions and trigger apoptosis, as well as to repair the nucleic acid structure and allow cancer cell survival (46-48). Parallel to this, cancer cells undergoing apoptosis lose their membrane integrity and release molecules that are constitutive of the cellular frame-work (46-48). In addition, it has been demonstrated that the tumoral resistance toward anticancer platinum complexes can be increased by high concentrations of thiol-containing molecules, such as methionine (49), cysteine, glutathione (50) and metallothioneins (51). Taken together, these cellular events induce strong qualitative and quantitative modifications of the cellular content of the above-mentioned compounds. It is therefore expected that the 'chemical signature' of cancer cells after treatment with the complexes could be different when the mechanisms of action or resistance are divergent, which is why we used a FTIR approach in the current study to investigate whether the chemical signatures in whole cancer cells (we chose the A549 NSCLC cell line as a model, 31) would significantly differ from the novel compounds (compounds 4, 5, 6, 8, 9 and 10 in Fig. 1) generated from compound 7 as a scaffold (Fig. 1). 
The determination of the $\mathrm{IC}_{50}$ in vitro growth inhibitory concentration by means of two distinct tests (Tables I and II, Fig. 2) suggested that the anticancer activity displayed by all compounds under study were roughly similar, at least in vitro. FTIR analyses then revealed that the mechanisms of action of the novel compounds we generated did not actually diverge from that displayed by compound 7 , as illustrated in Fig. 3. Fig. 3B shows that compound 7 presented the largest spectral dissimilarities when compared with the spectra of untreated cells. Fig. 3D shows different spectra characterizing metabolic changes induced by each molecule tested in this study. Compound 7 clearly led to the deepest metabolic changes in intensity, as well as in the number of wavenumbers that significantly differed $(\alpha=0.5 \%)$. The main changes appeared between 1765 and $1500 \mathrm{~cm}^{-1}$ in the spectral range. This area is mainly dominated by contributions arising from lipids [around $1740 \mathrm{~cm}^{-1}$ (37)] and proteins [the Amide I and II, roughly comprised between 1700 and $1500 \mathrm{~cm}^{-1}$ (37)]. Difference peaks were positive, suggesting that A549 NSCLC cells were enriched in these two components against the rest of the cellular content after incubation with compound 7.

In conclusion, we proposed to combine an in vitro assay to determine the $\mathrm{IC}_{50}$ growth inhibitory concentrations of a series of compounds belonging to a given chemical series and FTIR analyses carried out at the $\mathrm{IC}_{50}$ concentrations for each compound to identify potential hits within this series of compounds. The current study showed that we did not obtain a lead with a significant divergent activity when modifying a novel platinum derivative. Interestingly, the original pharmacology approach proposed here could avoid large-scale pharmacological experiments to find hits within a given chemical series.

\section{Acknowledgements}

R.K. and E.G. are Directors of Research with the Fonds National de la Recherche Scientifique (FNRS, Belgium). R.G. was supported by a grant from the Interuniversity Attraction Pole (IAP) P6/19 (Belgium).

\section{References}

1. Kelland LR: The resurgence of platinum-based cancer chemotherapy. Nat Rev Cancer 7: 573-584, 2007.

2. Galanski M: Recent developments in the field of anticancer platinum complexes. Recent Patents Anti-Cancer Drug Discov 1: 285-295, 2006.

3. Shah N and Dizon DS: New-generation platinum agents for solid tumors. Future Oncol 5: 33-42, 2009.

4. McKeage MJ: Comparative adverse effect profiles of platinum drugs. Drug Saf 13: 228-244, 1995.

5. Giaccone G: Clinical perspectives on platinum resistance. Drugs 59: S9-S17, 2000

6. O'Dwyer PJ, Stevenson JP and Johnson SW: Clinical pharmacokinetics and administration of established platinum drugs. Drugs 59: S19-S27, 2000.

7. Galanski M, Jakupec MA and Keppler BK: Oxaliplatin and derivatives as anticancer drugs-novel design strategies. In: Metal Compounds in Anticancer Chemotherapy. Perez JM, Fuertes MA and Alonso C (eds). Research Singpost, Kerala, pp155-185, 2005.

8. Stordal B, Pavlakis N and Davey R: Oxaliplatin for the treatment of cisplatin-resistant cancer: A systematic review. Cancer Treat Rev 33: 347-357, 2007.
9. Culy CR, Clemett D and Wiseman LR: Oxaliplatin. Drugs 60: 895-924, 2000.

10. Hall MD and Hambley TW: Platinum (IV) antitumour compounds; their bioorganic chemistry. Coord Chem Rev 232: 49-67, 2002.

11. Coluccia M and Natile G: Trans-platinum complexes in cancer therapy. Anti-Cancer Agents Med Chem 7: 111-123, 2007.

12. Farrell NP: Polynuclear charged platinum compounds as a new class of anticancer agents: toward a new paradigm. In: PlatinumBased Drugs in Cancer Therapy. Kelland LR and Farrell NP (eds). Humana Press, Totowa, New Jersey, pp321-338, 2000.

13. Van Zutphen $\mathrm{S}$ and Reedijk J: Targeting platinum anti-tumour drugs: Overview of strategies employed to reduce systemic toxicity. Coord Chem Rev 249: 2845-2853, 2005.

14. Jung YW and Lippard SJ: Direct cellular responses to platinuminduced DNA damage. Chem Rev 107: 1387-1407, 2007.

15. Siddik ZH: Cisplatin: mode of cytotoxic action and molecular basis of resistance. Oncogene 22: 7265-7279, 2003.

16. Gust R, Gelbcke M, Angermaier B, Bachmann H, Krauser R and Schöhenberger $\mathrm{H}$ : The stereoselectivity of antitumor active [1,2-diamino-1-phenylpropane]dichloroplatinum(II) complexes. Inorg Chim Acta 264: 145-160, 1997.

17. Dufrasne F, Gelbcke M, Schnurr B and Gust R: Synthesis and antitumor activity of enantiomerically pure [1,2-diamino-1-(4fluorophenyl)propane]dichloroplatinum(II) complexes. Arch Pharm 335: 229-239, 2002.

18. Dullin A, Dufrasne F, Gelbcke M and Gust R: Enantiomerically pure [1,2-diamino-1-(4-fluorophenyl)butane]platinum(II) complexes: Synthesis and antitumor activity against MCF-7 and MDA-MB 231 breast cancer and LnCaP/FGC prostate cancer cell lines. Arch Pharm 337: 654-667, 2004.

19. Dullin A, Dufrasne F, Gelbcke M and Gust R: Synthesis and cytotoxicity of enantiomerically pure [1,2-diamino-1-(4-fluorophenyl)-3-methylbutane]platinum(II) complexes. ChemMedChem 1: 644-653, 2006.

20. Gasper R, Dewelle J, Kiss R, Mijatovic T and Goormaghtigh E: IR spectroscopy as a new tool for evidencing antitumor drug signatures. Biochim Biophys Acta - Biomembranes 1788: 1263-1270, 2009.

21. Matier WL, Owens DA, Comer WT, Deitchman D, Ferguson HC, Seidehamel RJ and Young JR: Antihypertensive agents. synthesis and biological properties of 2-amino-4-aryl-2-imidazolines. J Med Chem 16: 901-908, 1973.

22. Gust R, Lubczyk V, Schmidt K and Shihada U: Synthesis, conformational studies, and investigations on the estrogen receptor binding of [R/S-1-(2,6-dichloro-4hydroxyphenyl)ethylenediamine]platinum (II) complexes. Arch Pharm 334: 93-100, 2001

23. Van Quaquebeke E, Simon G, Andre A, Dewelle J, Yazidi ME, Bruyneel F, Tuti J, Nacoulma O, Guissou P, Decaestecker C, Braekman JC, Kiss R and Darro F: Identification of a novel cardenolide (2"-oxovorusharin) from Calotropis procera and the hemisynthesis of novel derivatives displaying potent in vitro anti-tumor activities and high in vivo tolerance: Structure-activity relationship analyses. J Med Chem 48: 849$856,2005$.

24. Ozalp-Yaman S, de Hoog P, Amadei G, Pitié M, Gamez P, Dewelle J, Mijatovic T, Meunier B, Kiss R and Reedijk J: Platinated copper (3-clip-phen) complexes as effective DNA-cleaving and cytotoxic agents. Chemistry-Eur J 14: 3418-3426, 2008.

25. Lamoral-Theys D, Andolfi A, Van Goietsenoven G, Cimmino A, Le Calvé $\mathrm{B}$, Wauthoz $\mathrm{N}$, Mégalizzi $\mathrm{V}$, Gras T, Bruyère $\mathrm{C}$, Dubois J, Mathieu V, Kornienko A, Kiss R and Evidente A: Lycorine, the main phenanthridine Amaryllidaceae alkaloid, exhibits significant antitumor activity in cancer cells that display resistance to proapoptotic stimuli: An investigation of structureactivity relationship and mechanistic insight. J Med Chem 52: 6244-6256, 2009

26. Bernhardt G, Reile H, Birnböck H, Spruss $T$ and Schöneneberger $\mathrm{H}$ : Standardized kinetic microassay to quantify differential chemosensitivity on the basis of proliferative activity. J Cancer Res Clin Oncol 118: 35-43, 1992.

27. Reile H, Birnböck H, Bernhardt G, Spruss T and Schönenberger H: Computerized determination of growth kinetic curves and doubling times from cells in microcultures. Anal Biochem 187: 262-267, 1990

28. Gaigneaux A, Decaestecker C, Camby I, Mijatovic T, Kiss R, Ruyschaert JM and Goormaghtigh E: The infrared spectrum of human glioma cells is related to their in vitro and in vivo behavior. Exp Cell Res 297: 294-301, 2004. 
29. Lefranc F, Mijatovic T, Kondo Y, Sauvage S, Roland I, Krstic D, Vasic V, Gailly P, Kondo S, Blanco G and Kiss R: Targeting the alpha- 1 subunit of the sodium pump (the $\mathrm{Na}^{+} / \mathrm{K}^{+}$-ATPase) to combat glioblastoma cells. Neurosurgery 62: 211-222, 2008.

30. Ingrassia L, Lefranc F, Dewelle J, Pottier L, Mathieu V, SpieglKreinecker S, Sauvage S, El Yazidi M, Dehoux M, Berger W, Van Quaquebeke E and Kiss R: Structure-activity-relationship analysis of novel derivatives of narciclasine (an Amaryllidaceae Isocarbostyril alkaloid) as potential anti-cancer agents. J Med Chem 52: 1100-1114, 2009.

31. Mijatovic T, Mathieu V, Gaussin JF, De Neve N, Ribaucour F, Van Quaquebeke E, Dumont P, Darro F and Kiss R: Cardenolideinduced lysosomal membrane permeabilization contributes therapeutic benefits in experimental human non-small-cell-lung cancers. Neoplasia 8: 402-412, 2006.

32. Mathieu V, Pirker C, Martin de Lassalle E, Vernier M, Mijatovic T, DeNeve N, Gaussin JF, Dehoux M, Lefranc F, Berger W and Kiss R: The sodium pump alpha-1 subunit: a disease progression-related target for metastatic melanoma treatment. J Cell Mol Med 9: 3960-3972, 2010.

33. Bruyère C, Mijatovic T, De Nève N, Gaussin JF, Gras T, Nindfa P, Dehoux M, Saussez S and Kiss R: Combining proapoptotic or pro-autophagic chemotherapies with chemokine inhibition in experimental esophageal cancers. Proc Am Assoc Cancer Res, Abst 4135, 2009.

34. Dumont P, Ingrassia L, Rouzeau S, Ribaucour F, Thomas S, Roland I, Darro F, Lefranc F and Kiss R: The Amaryllidaceae isocarbostyril narciclasine induces apoptosis by activation of the Death Receptor and/or the mitochondrial pathways in cancer cells but not in normal fibroblasts. Neoplasia 9: 766776, 2007.

35. Branle F, Lefranc F, Camby I, Jeuken J, Geurts-Moespot A, Sprenger S, Sweep F, Kiss R and Salmon I: Evaluation of the efficiency of chemotherapy in in vivo orthotopic models of human glioma cells with and without $1 \mathrm{p} / 19 \mathrm{q}$ deletions and in C6 rat orthotopic allografts serving for the evaluation of surgery combined with chemotherapy. Cancer 95: 641-655, 2002.

36. Bruggisser R, von Daeniken K, Jundt G, Schaffer W and Tullberg-Reinert H: Interference of plant extracts, phytoestrogens and antioxydants with the MTT tetrazolium assay. Planta Med 68: 445-448, 2002.
37. Naumann D: Infrared spectroscopy in microbiology. In: Encyclopedia of Analytical Chemistry. Meyers RA (ed). John Wiley \& Sons Ltd, Chichester, pp102-131, 2000.

38. Teicher BA: Newer cytotoxic agents: attacking cancer broadly. Clin Cancer Res 14: 1610-1617, 2008.

39. Chen D, Milacic V, Frezza M and Dou QP: Metal complexes, their cellular targets and potential for cancer therapy. Curr Pharm Des 15: 777-791, 2009.

40. Zhang J, Liu D, Li Y, Sun J, Wang L and Zang A: Status of non-classical mononuclear platinum anticancer drug development. Mini Rev Med Chem 9: 1357-1366, 2009.

41. Cassidy J and Misset JL: Oxaliplatin-related side effects: characteristics and management. Semin Oncol 29: 11-20, 2002.

42. Bhargava A and Vaishampayan UN: Satraplatin: leading the new generation of oral platinum agents. Expert Opin Investig Drugs 18: 1787-1797, 2009.

43. Montana AM and Batalla C: The rational design of anticancer platinum complexes: the importance of the structure-activity relationship. Curr Med Chem 16: 2235-2260, 2009

44. Hambley TW: The influence of structure on the activity and toxicity of Pt anticancer drugs. Coord Chem Rev 166: 181-223 (1997)

45. Jamieson E and Lippard SJ: Structure, recognition, and processing of cisplatin-DNA adducts. Chem Rev 99: 2467-2498, 1999.

46. Pani E, Stojic L, El-Shemerly M, Jiricny J and Ferrari S: Mismatch repair status and the response of human cells to cisplatin. Cell Cycle 6: 1796-1802, 2007.

47. Beretta GL, Gatti L, Corna E, Carenini N, Zunino F and Perego P: Defining targets of modulation of human tumor cell response to cisplatin. J Inorg Biochem 102: 1406-1415, 2008.

48. Zlatanova J, Yaneva J and Leuba SH: Proteins that specifically recognize cisplatin-damaged DNA: a clue to anticancer activity of cisplatin. FASEB J 12: 791-799, 1998.

49. Vrana $\mathrm{O}$ and Brabec V: L-methionine inhibits reaction of DNA with anticancer cis-diamminedichloroplatinum(II). Biochemistry 41: 10994-10999, 2004.

50. Rabik C and Dolan ME: Molecular mechanisms of resistance and toxicity associated with platinating agents. Cancer Treat Rev 33: 9-23, 2007.

51. Knipp M: Metallothioneins and platinum(II) anti-tumor compounds. Curr Med Chem 16: 522-537, 2009. 